Research article

\title{
Quantitative forecasting black (pyrogenic) carbon in soils by chemometric analysis of infrared spectra
}

\author{
José M. De la Rosa ${ }^{\mathrm{a}, 1}$, Marco A. Jiménez-González ${ }^{\mathrm{b}, *, 1}$, Nicasio T. Jiménez-Morillo ${ }^{\mathrm{c}, \mathrm{d}}$, \\ Heike Knicker ${ }^{\mathrm{a}}$, Gonzalo Almendros ${ }^{\mathrm{b}}$ \\ a Instituto de Recursos Naturales y Agrobiología de Sevilla, Consejo Superior de Investigaciones Científicas (IRNAS-CSIC), Reina Mercedes Av., 10, 41012, Seville, Spain \\ ${ }^{\mathrm{b}}$ Museo Nacional de Ciencias Naturales, Consejo Superior de Investigaciones Científicas (MNCN-CSIC), Serrano 115B, 28006, Madrid, Spain \\ ${ }^{\mathrm{c}}$ Hercules Laboratory, University of Évora, Largo Marquês do Vimioso, 8, 7000-809, Évora, Portugal \\ ${ }^{\mathrm{d}}$ ICAAM - Instituto de Ciências Agrárias e Ambientais Mediterrânicas, IIFA, Universidade de Évora, Núcleo da Mitra, Ap. 94, 7006-554, Évora, Portugal
}

\section{A R T I C L E I N F O}

\section{Keywords:}

Carbon stabilization

Black carbon

Partial least squares regression

\begin{abstract}
A B S T R A C T
A detailed and global quantitative assessment of the distribution of pyrogenic carbon (PyC) in soils remains unaccounted due to the current lack of unbiased methods for its routine quantification in environmental samples. Conventional oxidation with potassium dichromate has been reported as a useful approach for the determination of recalcitrant $\mathrm{C}$ in soils. However, its inaccuracy due to the presence of residual non-polar but still non-PyC requires additional analysis by ${ }^{13} \mathrm{C}$ solid-state nuclear magnetic resonance (NMR) spectroscopy, which is expensive and time consuming. The goal of this work is to examine the possibility of applying infrared (IR) spectroscopy as a potential alternative. Different soil type samples (paddy soil, Histic Humaquept, Leptosol and Cambisol) have been used. The soils were digested with potassium dichromate to determine the PyC content in environmental samples. Partial Least Squares (PLS) regression was used to build calibration models to predict PyC from IR spectra. A set of artificially produced samples rich in PyC was used as reference to observe in detail the IR bands derived from aromatic structures resistant to dichromate oxidation, representing black carbon. The results showed successful PLS forecasting of PyC in the different samples by using spectra in the $1800-400 \mathrm{~cm}^{-1}$ range. This lead to significant $(P<0.05)$ cross-validation coefficients for PyC, determined as the aryl C content of the oxidized residue. The Variable Importance for Projection (VIP) traces for the corresponding PLS regression models plotted in the whole IR range indicates the extent to which each IR band contributes to explain the aryl C and PyC contents. In fact, forecasting PyC in soils requires information from several IR regions. In addition to the expected IR bands corresponding to aryl C, other bands are informing about the patterns of oxygen-containing functional groups and the mineralogical composition characteristic of the soils with greater black carbon storage capacity. The VIP traces of the charred biomass samples confirm that aromatic bands $\left(1620\right.$ and $\left.1510 \mathrm{~cm}^{-1}\right)$ are the most important in the prediction model for PyC-rich samples. These facts suggest that the mid-IR spectroscopy could be a potential tool to estimate the black carbon.
\end{abstract}

\section{Introduction}

Up to three different pools of soil organic matter (SOM) are typically distinguished in terms of its stability in environmental conditions, viz, labile, mid and strongly refractory (De la Rosa et al., 2008a; Poirier et al., 2000). The least labile fraction is abundant in pyrogenic C (PyC; also called charcoal or black carbon), which has been thermally altered and is expected to be highly resistant against chemical and biological degradation (Masiello and Druffel, 1998; Schmidt and Noack, 2000). Therefore, the PyC-containing soils are expected to represent an important sink within the global C-cycle (De la Rosa et al., 2008b; Lasslop et al., 2019; Jones et al., 2019; Santin et al., 2016) and would therefore play a relevant role in the recent " 4 per mil" initiative (https://www.4p1000.org), which recognizes the pivotal role of soil in carbon sequestration. In order to properly elucidate the impact of $\mathrm{PyC}$ in soil biogeochemical cycle, its accurate detection and quantification is essential. However, both local and global spatial distribution patterns of PyC in soils is still missing due to the current lack of reliable methods for its routine quantification in environmental samples. This problem is related to the fact that PyC represents a wide continuum and modern

\footnotetext{
* Corresponding author.

E-mail address: majimenez@mncn.csic.es (M.A. Jiménez-González).

${ }^{1}$ Both authors contributed equally.
} 
approaches are often restricted to the detection of compounds in a certain window of molecular range. A further problem is related to difficulties to distinguish at a molecular level between residues derived from unburnt sources (natural organic matter NOM) and PyC components. In fact, degradative techniques are often applied for their separation but most of them show limited selectivity. The alternative use of non-degradative methods, such as solid-state nuclear magnetic resonance (NMR) spectroscopy, results in spectra in which the signals of PyC and NOM are difficult to be distinguished in bulk samples. For this reason, current contents on PyC in soil may have been underestimated to a large extent in classical studies (De la Rosa et al., 2011). In fact, accurate quantification of $\mathrm{PyC}$ would provide data required for consistent modelling of soil C turnover as well as to properly assess the soil potential for $\mathrm{C}$ sequestration. Preliminary intercomparative studies reported that a combination of several complementary analytical tools is essential to detect the whole continuum of combustion products (De la Rosa et al., 2011; Hammes et al., 2007; Leng et al., 2019).

In order to circumvent this problem, a simple wet chemical oxidation method with $0.1 \mathrm{M}$ potassium dichromate has been suggested for isolating PyC in soils (Knicker et al., 2007). Nevertheless, due to the fact that non-polar compounds such as lipids derived from NOM are not completely degraded by the chemical oxidation and thus remain in the nonhydrolyzable residue, the accurate quantification of PyC requires further application of solid-state ${ }^{13} \mathrm{C}$ nuclear magnetic resonance (NMR) spectroscopy to the oxidation residue. With this approach, the abundance of $\mathrm{PyC}$ is calculated from the relative signal area of the ${ }^{13} \mathrm{C}$ NMR aromatic $\mathrm{C}$ region of oxidation residue spectrum, which is referred to the total $\mathrm{C}$ in the untreated soil after the application of a correction factor. This experimental approach takes into account that polar groups (phenols or carboxylic aromatic residues) are attacked by the acid (Knicker et al., 2007). Nonetheless, considering the low availability of solid-state NMR spectrometer time which is also expensive alternatives are needed. Therefore, the present study is an attempt to routinely apply Fourier transform (FT) infrared (IR) spectroscopy to natural samples after chemical oxidation to assess the proportion of PyC.

Infrared spectroscopy is a non-destructive technique widely used for the structural characterization of SOM (Jiménez-González et al., 2019; Parolo et al., 2017; Terra et al., 2019). For general purposes, the relative intensity of IR spectral bands may be successfully used in chemometric studies based on semi-quantitative data (Fernández-Getino et al., 2010; Sisouane et al., 2017). In fact, such data are valid to compare the intensity of the same band in different spectra, although not to compare proportions of different functional groups based on different bands in the same spectrum. A realistic alternative for the quantitative analysis of SOM components based in processing IR spectra is using suitable multivariate chemometric approaches (Russell et al., 2019). The partial least squares (PLS) regression, using the whole spectral data points as descriptors, is a more accurate method of extracting underlying chemometric information from IR spectra, than simply digitizing large number of individual bands. Up to now, several attempts have been developed in bulk soil samples with contrasting outcomes. Zimmermann et al. (2007) demonstrated that the amount of chemically recalcitrant $\mathrm{SOM}$ after $\mathrm{NaOCl}$ oxidation could be predicted from IR spectroscopic data processed by multivariate data analyses such as PLS regression. Similar results were obtained by Leifeld (2006), who successfully predicted the alkyl and carboxyl C NMR intensities in SOM whereas the prediction of aromatic signals failed. At this point, the application of derivative spectroscopy may represent some improvement in avoiding subjective judgements in baseline tracing, required to obtain comparable data for peak intensities in series of spectra (Michaell, 1988; Hernández and Almendros, 2012). In addition, as we are particularly interested in the sources of information suitable to identify and quantify the resistant fraction of soil C, the IR spectra of the material resistant to oxidation are also analysed in terms of the Variable Importance for Projection (VIP) values of each spectral data point, calculated during the PLS modelling. This index informs on the extent to which individual IR bands contribute to the PLS model, then illustrating soil components the concentration of which parallel that of the predicted dependant variable. Our hypothesis was that this approach could be used as a rapid, non-expensive and unsupervised alternative to NMR spectroscopy to evaluate PyC contents in soils after wet chemical oxidation.

The main goal in this work is to quantitatively assess PyC content in soils and to examine the extent to which specific IR bands reflect the abundance of PyC. This method would be of importance to assess the potential of the soils to store black carbon. For this reason, spectral data points of IR spectra of 41 samples from 3 widely different soil types treated with potassium dichromate (independent variables) are processed in addition to dependent variables corresponding to i) carbon content, ii) ${ }^{13} \mathrm{C}$ NMR spectroscopy and iii) PyC abundance calculated according to Knicker et al. (2007). In addition, and in order to validate the prediction model of PyC in soils and to discern the origin of the bands corresponding to PyC, a supplementary set of seven PyC-rich samples produced by charring lignocellulosic plant materials under controlled conditions were incorporated to the study.

\section{Materials and methods}

\subsection{Samples}

Three sets of soils from different locations in addition to a collection of 7 samples of artificially charred biomass were selected for this study (Table 1). The three sets of previously characterized soils consisted of ancient paddy soils from the Yangtze River Delta (China) (Cao et al., 2006), Histic Humaquept soil from Doñana National Park (Huelva, Spain) and Leptosol and Cambisol from Sierra de Aznalcóllar (Seville, Spain) (World Reference Base for Soil Resources, 2014) (Knicker et al., 2013).

In addition, samples of casein and organosolv spruce lignin supplied by a pulp and paper plant in Kelheim (Germany) were charred in porcelain crucibles in a muffle oven at $350{ }^{\circ} \mathrm{C}$ and $450{ }^{\circ} \mathrm{C}$ for $4 \mathrm{~min}$ under oxic conditions (Knicker, 2010). Finally, two additional char samples were obtained under the same conditions from Lolium perenne grass and chips of pine wood heated for 4 min (Knicker et al., 2007). Further details for each sort of samples are shown in Table 1. All samples were dried $\left(40^{\circ} \mathrm{C}\right)$, homogenised and passed through a $2 \mathrm{~mm}$ mesh sieve before demineralization and chemical oxidation.

\subsection{Demineralization and chemical oxidation}

For demineralization, bulk soil samples were treated with hydrofluoric acid (HF) according to Gonçalves et al. (2003). Briefly, $10 \mathrm{~g}$ of sample was shaken with $50 \mathrm{~cm}^{3}$ of $10 \%$ (w:w) HF for $12 \mathrm{~h}$ in polyethylene bottles. After centrifugation, the supernatants were siphoned off and discarded. The procedure was repeated five times at room temperature. The remaining residue was washed with $50 \mathrm{~cm}^{3}$ of deionized water, freeze-dried and weighted.

Oxidation with acid solution of $\mathrm{K}_{2} \mathrm{Cr}_{2} \mathrm{O}_{7}$ for PyC determination was based on Knicker et al. (2007). About $300 \mathrm{mg}$ HF-treated soils and the set of artificially charred materials was oxidized with $50 \mathrm{~cm}^{3}$ of $0.1 \mathrm{M}$ $\mathrm{K}_{2} \mathrm{Cr}_{2} \mathrm{O}_{7}-2 \mathrm{M} \mathrm{H}_{2} \mathrm{SO}_{4}$ solution at $60^{\circ} \mathrm{C}$ in an ultrasonic bath during $6 \mathrm{~h}$ in duplicate. The final residue was washed with deionized water, freezedried and weighted prior to elemental and spectroscopic analyses.

\subsection{Total $C$ analysis}

Total C of bulk soil samples and its oxidized residues was measured in triplicate by dry combustion $\left(975^{\circ} \mathrm{C}\right)$ using an Elementar Vario EL microanalyzer detecting $\mathrm{N}$ as $\mathrm{N}_{2}$ and $\mathrm{C}$ as $\mathrm{CO}_{2}$. Detection limits for $\mathrm{C}$ and $\mathrm{N}$ were 0.4 and $1 \mu \mathrm{g}$, respectively. The maximum standard deviation was $7 \%$ for $\mathrm{C}$ and $5 \%$ for $\mathrm{N}$. 


\subsection{Solid-state ${ }^{13} \mathrm{C}$-NMR spectroscopy}

Solid-state ${ }^{13} \mathrm{C}$ cross polarization-magic angle spinning (CP-MAS) NMR spectra of the samples were recorded with a Bruker Avance III $200 \mathrm{MHz}$ instrument (Bruker Instruments, Billerica, Massachusetts, USA), using $\mathrm{ZrO}_{2}$ rotors of $4 \mathrm{~mm}$ o.d. Magic angle spinning (MAS) was applied at $6.8 \mathrm{kHz}$ during cross polarization (CP) for ${ }^{13} \mathrm{C}$. The ${ }^{13} \mathrm{C}$ chemical shifts are referenced to tetramethylsilane and adjusted with glycine. A contact time of $1 \mathrm{~ms}$ and a pulse delay of $500 \mathrm{~ms}$ were used. For each sample between 10,000 and 200,000 FIDs were accumulated to increase the signal/noise ratio of the NMR spectra. The spectra were integrated into six chemical shift regions: alkyl C (0-45 ppm); $N$-alkyl/ methoxyl C (45-60 ppm); O-alkyl C (60-90 ppm); aryl C (90-140 ppm); $O$-aryl C (140-160 ppm); carbonyl/amide C (160-250 ppm). The Bruker WinNMR software was used to measure peak areas.

\subsection{Fourier Transform-IR spectroscopy}

Fourier transform-infrared spectra were obtained using a JASCO 4100 spectrometer (Jasco Corporation, Tokio, Japan) at a wavelength range of $4000-400 \mathrm{~cm}^{-1}$ and a resolution of $2 \mathrm{~cm}^{-1}$. Potassium bromide pellets containing $2 \mathrm{mg}$ of powdered sample and $200 \mathrm{mg}$ of $\mathrm{KBr}$ were scanned. In order to improve the signal to noise ratio, 60 spectra were co-added and averaged for each recorded spectrum. Spectral data were background corrected to a reference spectrum prior to every measurement and some spurious absorptions, such as peaks from atmospheric $\mathrm{CO}_{2}$ were removed.

\subsection{Statistical analyses}

Partial least squares regression models were carried out by using the ParLeS software (Viscarra-Rossel, 2008). This program was used to obtain prediction models for each of the dependent variables (viz, PyC, aryl $\mathrm{C}$ region and alkyl $\mathrm{C}$ region of NMR) from the information contained in independent variables consisting of arrays with the spectral intensities in the range $1800-400 \mathrm{~cm}^{-1}$ (116 data points). Prior to PLS regression, the spectral pre-processing treatments available in the program ParLeS were checked, to finally select: a) light scatter and baseline correction by Standard Noise Variate (SNV), b) de-noising with a median filter rank of 2, and c) 2nd derivative transformation. Mean centering was also selected as further data pretreatment before PLS analysis. To select the best number of latent variables for each model, in order to prevent overfitting, the root mean squared error (RMSE) and the Akaike's information criterion (Akaike, 1974) were used. In addition, the selected PLS models were validated by a stricter criterion consisting of comparing the PLS cross-validation tests (observed vs calculated) with those performed with the same number of latent variables and the same matrix of independent variables but after random permutation of the data of the dependent variable (i.e., checking that no significant $(P<0.01)$ cross validation plot is obtained with the randomized values (Supplementary Fig. 1). Finally, for the significant PLS model selected, the diagnostic spectral regions of the IR spectra were studied by plotting the VIP values in the $1800-400 \mathrm{~cm}^{-1}$ spectral range studied. These VIP traces are considered to reflect quantitatively the contribution of each independent variable to the prediction model, then they can be useful to identify which spectral peaks may be acting as surrogates of the concentration in the soil of the dependent variable under study.

\section{Results and discussion}

\subsection{Carbon content and calculation of $P y C$ by ${ }^{13} \mathrm{C} N M R$ spectroscopy}

The PyC content was calculated for all samples by multiplying the relative intensity of the aryl $\mathrm{C}$ region of the ${ }^{13} \mathrm{C}$ NMR spectra with the organic carbon (OC) content after acid oxidation with potassium 
Table 2

Analytical characteristics determined in the samples.

\begin{tabular}{|c|c|c|c|c|c|c|c|}
\hline Samples & $\begin{array}{l}\text { Carbon content of bulk } \\
\text { samples }\left(\% ; C_{i}\right)\end{array}$ & $\begin{array}{l}\text { Yield (material after } \\
\text { oxidation; \%) }\end{array}$ & $\begin{array}{l}\text { Carbon content after } \\
\text { oxidation }(\%)\end{array}$ & $\begin{array}{l}\mathrm{C} \text { yield }(\% \text { of } \\
\left.\mathrm{C}_{\mathrm{i}}\right)\end{array}$ & $\begin{array}{l}\text { Aryl C }\left({ }^{13} \mathrm{C} \text { NMR }\right. \\
\text { sp; \%) }\end{array}$ & $\begin{array}{l}\text { Alkyl C }\left({ }^{13} \mathrm{C} \text { NMR }\right. \\
\text { sp; \%) }\end{array}$ & $\begin{array}{l}\text { PyC (\%) from } \\
\text { total }\end{array}$ \\
\hline Doñana_S1 & 6.4 & 87.0 & 1.5 & 20.5 & 26.6 & 46.8 & 5.5 \\
\hline Doñana_S2 & 2.7 & 93.0 & 0.6 & 21.7 & 40.3 & 35.6 & 8.7 \\
\hline Doñana_S3 & 8.0 & 87.0 & 2.1 & 22.7 & 18.1 & 65.2 & 4.1 \\
\hline Doñana_S4 & 3.3 & 95.0 & 0.9 & 24.2 & 22.4 & 56.0 & 5.4 \\
\hline Doñana_S5 & 1.8 & 98.0 & 0.4 & 24.1 & 42.3 & 36.1 & 10.2 \\
\hline Doñana_S6 & 1.0 & 100.0 & 0.2 & 21.6 & 61.5 & 16.8 & 13.3 \\
\hline Doñana_S7 & 4.3 & 86.0 & 0.5 & 10.2 & 20.6 & 45.0 & 2.1 \\
\hline Doñana_S8 & 1.5 & 97.0 & 0.4 & 22.2 & 42.3 & 30.5 & 9.4 \\
\hline Doñana_S9 & 0.4 & 100.0 & 0.1 & 23.8 & 64.8 & 18.7 & 15.4 \\
\hline Doñana_S10 & 29.3 & 43.0 & 9.0 & 13.2 & 4.0 & 80.2 & 0.5 \\
\hline Doñana_S11 & 4.1 & 91.0 & 0.8 & 17.6 & 22.0 & 57.9 & 3.9 \\
\hline Doñana_S12 & 1.8 & 95.0 & 0.4 & 19.1 & 35.0 & 38.5 & 6.7 \\
\hline Doñana_S13 & 2.1 & 96.0 & 0.5 & 23.1 & 34.0 & 44.1 & 7.8 \\
\hline Paddy_S1 & 8.7 & 25.0 & 6.9 & 19.9 & 39.0 & 30.8 & 7.8 \\
\hline Paddy_S2 & 7.1 & 26.0 & 7.8 & 28.6 & 57.0 & 14.3 & 16.3 \\
\hline Paddy_S3 & 19.7 & 36.0 & 16.2 & 29.6 & 59.0 & 21.6 & 17.4 \\
\hline Paddy_S4 & 11.9 & 32.0 & 10.9 & 29.5 & 41.0 & 38.1 & 12.1 \\
\hline Paddy_S5 & 3.7 & 13.0 & 5.8 & 20.4 & 41.0 & 38.1 & 8.3 \\
\hline Paddy_S6 & 16.7 & 25.0 & 18.0 & 24.0 & 29.0 & 14.2 & 7.0 \\
\hline Paddy_S7 & 2.7 & 27.0 & 5.0 & 17.0 & 42.0 & 10.6 & 7.1 \\
\hline Paddy_S8 & 19.7 & 31.0 & 20.2 & 31.9 & 64.7 & 9.6 & 20.6 \\
\hline Paddy_s9 & 4.1 & 13.0 & 6.9 & 21.8 & 35.8 & 34.5 & 7.8 \\
\hline Paddy_S10 & 13.8 & 25.0 & 10.8 & 19.6 & 47.2 & 25.3 & 9.2 \\
\hline Paddy_S11 & 7.4 & 24.0 & 8.5 & 27.7 & 47.2 & 25.3 & 13.1 \\
\hline Paddy_S12 & 6.4 & 26.0 & 6.0 & 24.3 & 45.8 & 16.7 & 11.1 \\
\hline Paddy_S13 & 5.9 & 23.0 & 6.1 & 23.8 & 44.2 & 24.7 & 10.5 \\
\hline Paddy_S14 & 13.4 & 24.0 & 13.7 & 24.6 & 62.8 & 10.6 & 15.4 \\
\hline Aznalcóllar_S1 & 18.0 & 60.0 & 27.1 & 42.4 & 66.0 & 10.3 & 28.0 \\
\hline Aznalcóllar_S2 & 11.3 & 56.0 & 19.7 & 30.8 & 59.3 & 15.3 & 18.3 \\
\hline Aznalcóllar_S3 & 12.8 & 47.2 & 19.0 & 34.7 & 60.3 & 20.4 & 20.9 \\
\hline Aznalcóllar_S4 & 1.4 & 29.6 & 15.4 & 7.2 & 22.2 & 54.3 & 1.6 \\
\hline Aznalcóllar_S5 & 7.3 & 31.6 & 20.4 & 26.4 & 35.3 & 35.0 & 9.3 \\
\hline Aznalcóllar_S6 & 8.1 & 24.0 & 16.5 & 24.8 & 12.3 & 58.4 & 3.0 \\
\hline Aznalcóllar_S7 & 6.7 & 26.6 & 21.6 & 19.4 & 11.7 & 65.5 & 2.3 \\
\hline Aznalcóllar_S8 & 5.3 & 32.8 & 18.5 & 20.1 & 46.9 & 35.1 & 9.4 \\
\hline Aznalcóllar_S9 & 7.1 & 28.6 & 18.0 & 24.6 & 29.7 & 47.3 & 7.3 \\
\hline Aznalcóllar_S10 & 5.3 & 38.9 & 17.0 & 18.6 & 42.5 & 37.6 & 7.9 \\
\hline Aznalcóllar_S11 & 5.2 & 8.9 & 25.8 & 9.1 & 5.9 & 70.2 & 0.5 \\
\hline Aznalcóllar_S12 & 7.0 & 18.7 & 16.9 & 17.6 & 13.3 & 55.9 & 2.3 \\
\hline Aznalcóllar_S13 & 5.9 & 25.7 & 15.2 & 23.1 & 21.0 & 49.5 & 4.9 \\
\hline Aznalcóllar_S14 & 4.6 & 29.6 & 11.5 & 20.2 & 22.1 & 59.2 & 4.5 \\
\hline Py_M1 & 65.8 & 17.4 & 50.5 & 13.3 & 52.6 & 23.4 & 7.0 \\
\hline Py_M2 & 62.9 & 86.6 & 59.4 & 81.7 & 82.0 & 9.9 & 67.0 \\
\hline Py_M3 & 47.0 & 24.2 & 48.4 & 24.9 & 73.6 & 8.4 & 18.3 \\
\hline Py_M4 & 30.7 & 34.0 & 45.5 & 50.3 & 75.4 & 0.0 & 37.9 \\
\hline Py_M5 & 57.2 & 55.4 & 60.9 & 58.9 & 78.6 & 3.2 & 46.3 \\
\hline Py_M6 & 66.2 & 55.8 & 67.1 & 56.5 & 65.3 & 17.1 & 36.9 \\
\hline Py_M7 & 64.3 & 77.0 & 69.0 & 82.6 & 87.0 & 6.9 & 71.9 \\
\hline
\end{tabular}

Aryl C: 90-160 ppm; Alkyl C: 0-45 ppm; PyC: pyrogenic C.

dichromate of the samples (Table 2). As expected, both the final weight of non-degraded residue after dichromate oxidation and the ${ }^{13} \mathrm{C}$ NMR signal area for aryl $\mathrm{C}$ varied widely depending on the origin of the samples. Residues of the topsoil samples from burned sites reached up to $65 \%$ of aryl C, which accounts for over $20 \%$ of PyC. In contrast, the samples from horizons below $30-40 \mathrm{~cm}$ depth of the unburnt sandy soils resulted in aryl C contents $\leq 20 \%$ and extremely low amounts of PyC (0-4\%). Fig. 1 shows ${ }^{13} \mathrm{C}$ NMR spectra of selected samples representative from each set of samples. Individually, the three sorts of soils also display a wide range of aromaticity. Another aspect shown by the ${ }^{13} \mathrm{C}$ NMR spectra is that SOM of alkyl nature is also resistant to the dichromate oxidation under the conditions used (Knicker et al., 2007), which confirms the need to discriminate the aromatic fraction in order to achieve a reliable assessment of PyC in soils. The laboratory-charred C-rich samples show a high aromaticity ( $>50 \%$ of total C), as expected from the origin of the samples, prepared to obtain materials representing the most common sources of pyrogenic organic matter in soils.

\subsection{IR spectroscopy and PLS analysis}

Fig. 2 displays the cross validation plots (linear regression between predicted and observed values) for the aromaticity and PyC content of each set of samples. Fig. 2a illustrates the possibility of predicting significantly the concentration of aryl $\mathrm{C}$ as determined by ${ }^{13} \mathrm{C}$ NMR spectroscopy, using exclusively the information contained in the $1800-400 \mathrm{~cm}^{-1}$ range of IR spectra from the dichromate-oxidized residues. The PLS models successfully predicted the percentages of aryl C in all sets of soils. The less significant prediction was for Histic Humaquept sandy soil $\left(R^{2}=0.67 ; P<0.05\right)$. This is probably related to its comparatively low organic $\mathrm{C}$ content $(<1 \%)$ and the possible interferences due to the heterogeneous mineral fraction. In the same way, the application of this IR approach also leads to significant prediction of PyC (Fig. 2b). In an attempt to extend the applicability of the model and considering the presence of SOM of alkyl nature resistant to degradation, Fig. 3 shows the correlation between the independent variables measured by IR and the relative abundance of alkyl C of each sample measured by ${ }^{13} \mathrm{C}$ NMR spectroscopy. The regression coefficients 


$\begin{array}{ccc}\text { Paddy soils } & \text { Histic Humaquept } & \text { Leptosols and } \\ \text { (Yangtze River } & \text { (Doñana) } & \text { Cambisols } \\ \text { Delta) } & & \text { (Aznalcóllar) }\end{array}$

\section{Pyrogenic C material} (laboratory-produced)

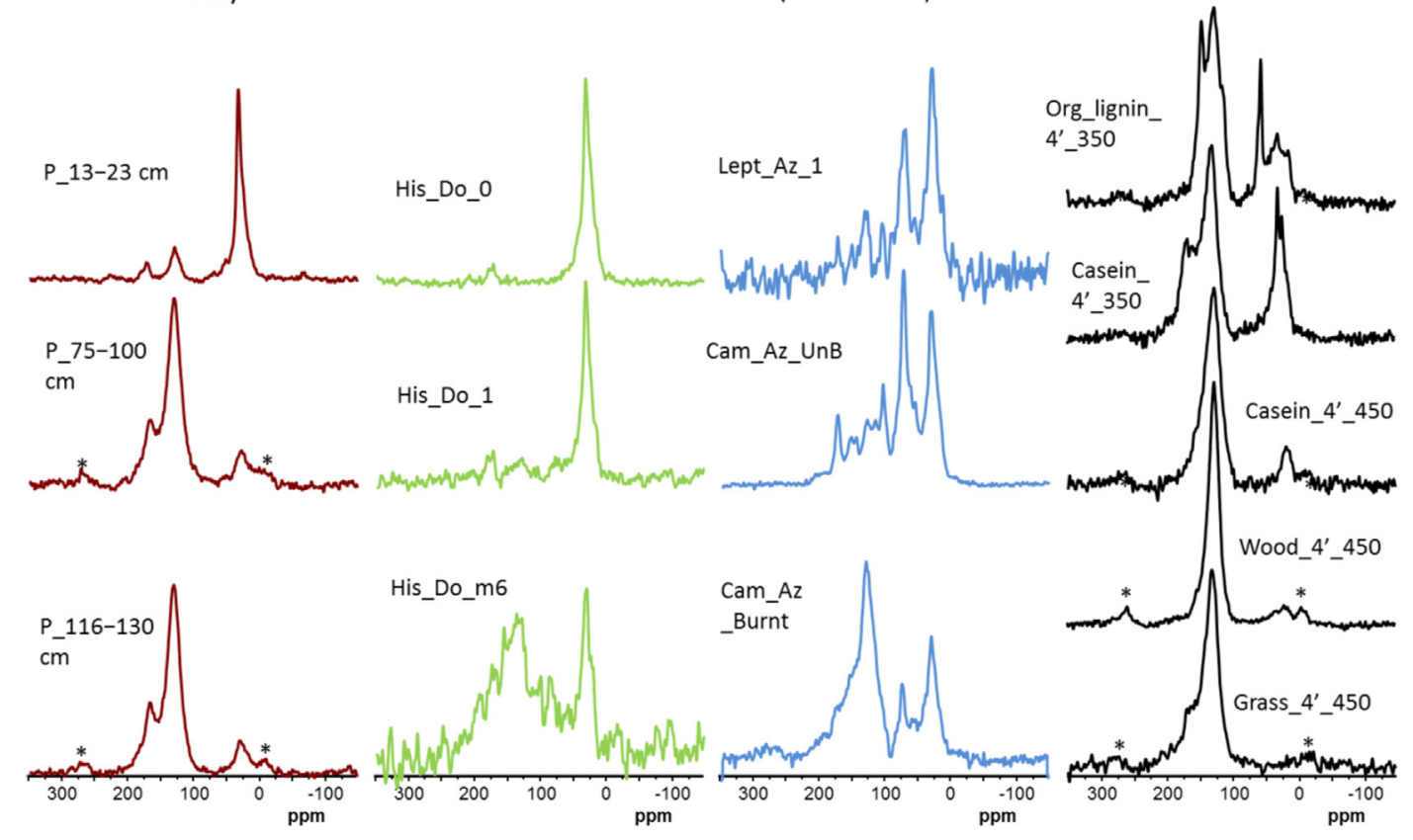

Fig. 1. Solid state ${ }^{13} \mathrm{C}$ NMR spectra of potassium dichromate-treated samples representative for the different sets of soils: Paddy soils (brown), Histic Humaquept (green), Leptosols and Cambisols (blue) and of the laboratory-produced pyrogenic materials (black). Spinning side bands are indicated with asterisks (*).

between the observed and predicted values were significant $\left(R^{2} \geq 0.74\right.$; $P<0.05$ ) in all cases except for the paddy soils, this fact could be due to the low variability of alkyl-C in this soils. Whereas soils from Doñana and Aznalcóllar showed proportions of alkyl $\mathrm{C}$ ranging between 30 to $80 \%$ and $20-70 \%$, respectively, the paddy soil showed values between 20 and $40 \%$.

\subsection{IR spectra and importance for PyC prediction}

The considerable differences in the environmental factors involved in the accumulation of SOM in the studied soils must necessarily result in wide diversity in the concentration and composition of the recalcitrant $\mathrm{C}$ forms. In this scenario, it is presumable that specific soil features are playing a key role in the preservation of the SOM as PyC intergrades. This could be examined by taking advantage of the VIP values calculated during the PLS. Fig. 4 shows the VIP traces for the different dependent variables. Such traces inform on the extent to which the different IR peaks contributed to the prediction of PyC and aryl C for each set of samples. This figure shows that the most determinant IR bands for predicting the aromaticity of the residue or its PyC content vary according to the type of soil, or the origin of the charred samples. It was also observed that the VIP pattern, calculated during the prediction of PyC and aryl C are very similar, which could be due to the close relationship between these two variables. While in the set of samples of pyrogenic-rich material the most important bands were found at ca. $1700-1750 \mathrm{~cm}^{-1}$ (acid and ester structures) and $1600-1640 \mathrm{~cm}^{-1}$ (aromatic and amide structures), the lowest importance was found in bands 1420, 1350 and $1230 \mathrm{~cm}^{-1}$ which are characteristic of the lignin pattern frequently found in the IR spectra of slightly humified SOM (Fengel and Wegener, 1984; Miralles et al., 2007).

In the case of the ancient paddy soil from China it seems that the prediction of the aromaticity of the digested material derives mainly from the IR bands ca. $1000-1100 \mathrm{~cm}^{-1}, 440-500 \mathrm{~cm}^{-1}$ and $1620-1690 \mathrm{~cm}^{-1}$, whereas the prediction of the PyC and aryl $\mathrm{C}$ values of the sandy soils from Doñana was essentially described by the broad band system between 1000 and $1100 \mathrm{~cm}^{-1}$ and to a lesser extent by $440,650,750$ and $1640 \mathrm{~cm}^{-1}$. A similar outcome was observed for the spectra from Leptosols/Cambisols of Aznalcóllar, dominated by bands over 440 and $500 \mathrm{~cm}^{-1}$. These bands are typically attributed to Si-O, $\mathrm{Fe}-\mathrm{O}$ and/or $\mathrm{Al}-\mathrm{O}$ groups in bulk soils, then suggesting a mineralogical control of PyC stabilization in soils. These results suggest that the different soil nature and mineral composition play an important role in relation to what SOM fraction is associated with the presence of the $\mathrm{PyC}$, maybe due to some organo-mineral interactions. For instance, in paddy soils the most differential predictor peaks (diagnostic region) for the PyC corresponded to bands attributed to carboxyl groups, aromatic structures and bands associated to minerals, whereas among Leptosol, Cambisol and Histic soils, the most differential ones correspond to minerals bands and to a lesser extent to carboxyl and aromatic bands. These differences in the association between PyC and SOM can be due to a contrasting origin of the PyC or different degree of transformation.

\section{Conclusions}

This study demonstrates that a prediction model based on PLS regression and on the information contained in the IR spectra is able to forecast the PyC content of contrasting soils and of artificially charred biomass. This approach showed its best predicting potential for soils with organic C concentrations greater than $1 \%$. The VIP values of the IR spectra show that forecasting PyC in soils requires information from several IR regions in a way that, in general, none of which shows a primary importance. In general, the most important bands for the prediction in the spectra from soils correspond to minerals resistant to demineralizing treatments under the conditions used and to a lesser extent to carboxyl and aromatic bands. This contrast with the case of artificially charred biomass which was used as reference for PyC rich samples where, as expected, aromatic bands centered at 1620 and $1510 \mathrm{~cm}^{-1}$ play a relevant role for the assessment of stable $C$ in soils. 

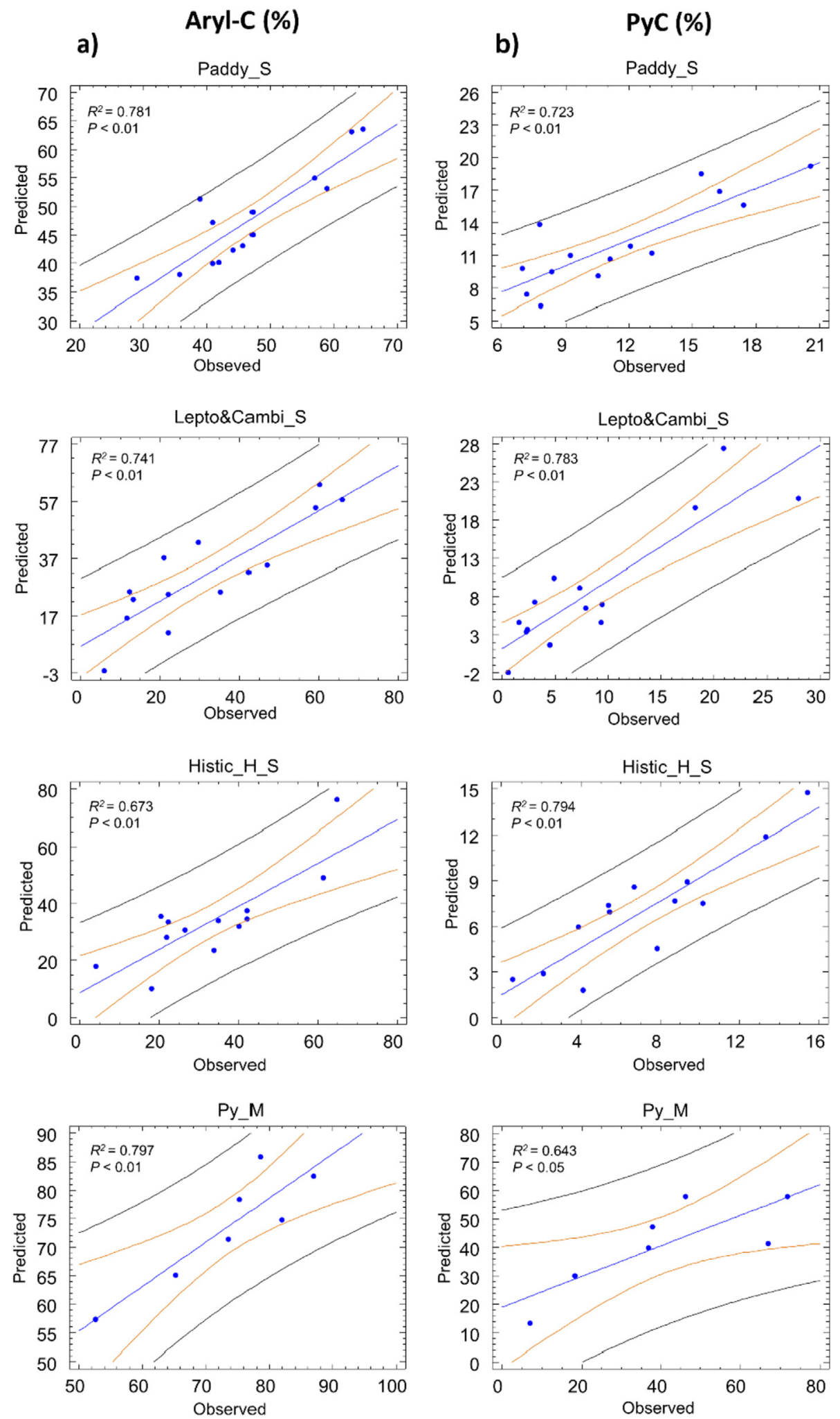

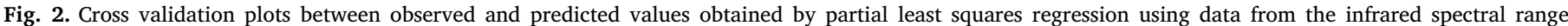

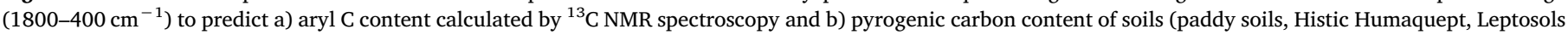
and Cambisols) and of laboratory-charred lignocellulosic biomass (Py_M).

\section{Acknowledgements}

José M. De la Rosa and Marco A. Jiménez-González thank the Spanish Ministry of Economy and Competitiveness (MINECO, Spain) for funding the "Ramón y Cajal" post-doctoral contract (RYC2014-16338) and the pre-doctoral FPI fellowship (BES-2014-069238) respectively. Nicasio T. Jiménez-Morillo was funded by the scholarship PosDoc/Por 30/OUT17 (FCT, Portugal). 


\section{Alkyl-C (\%)}
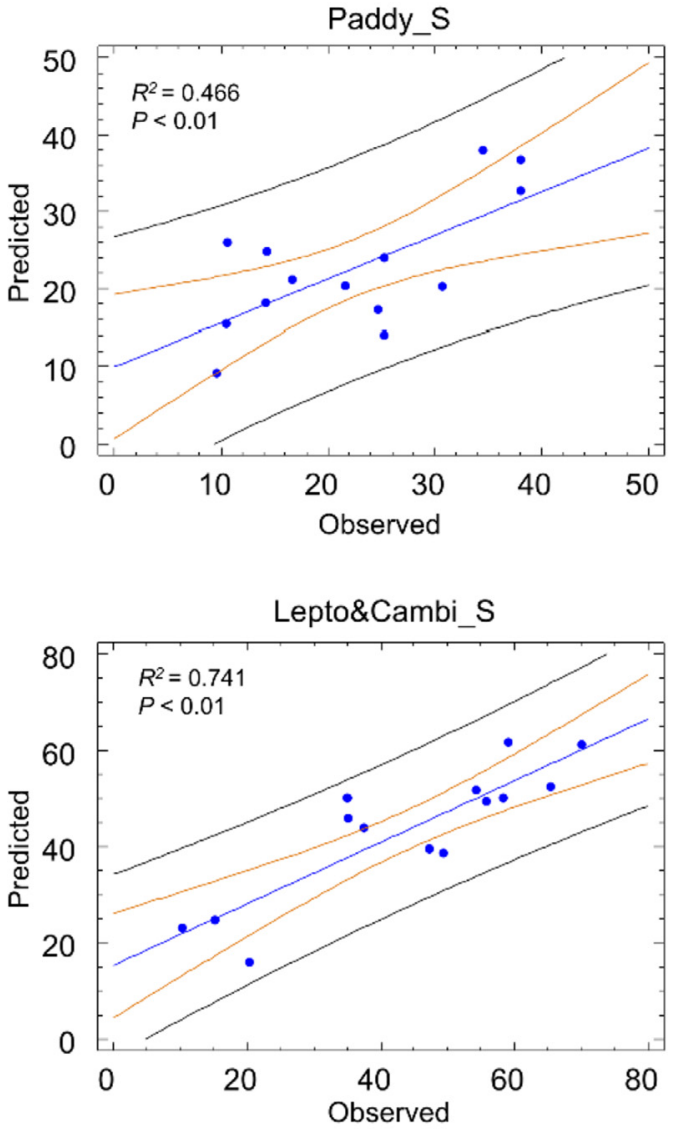

Histic_H_S
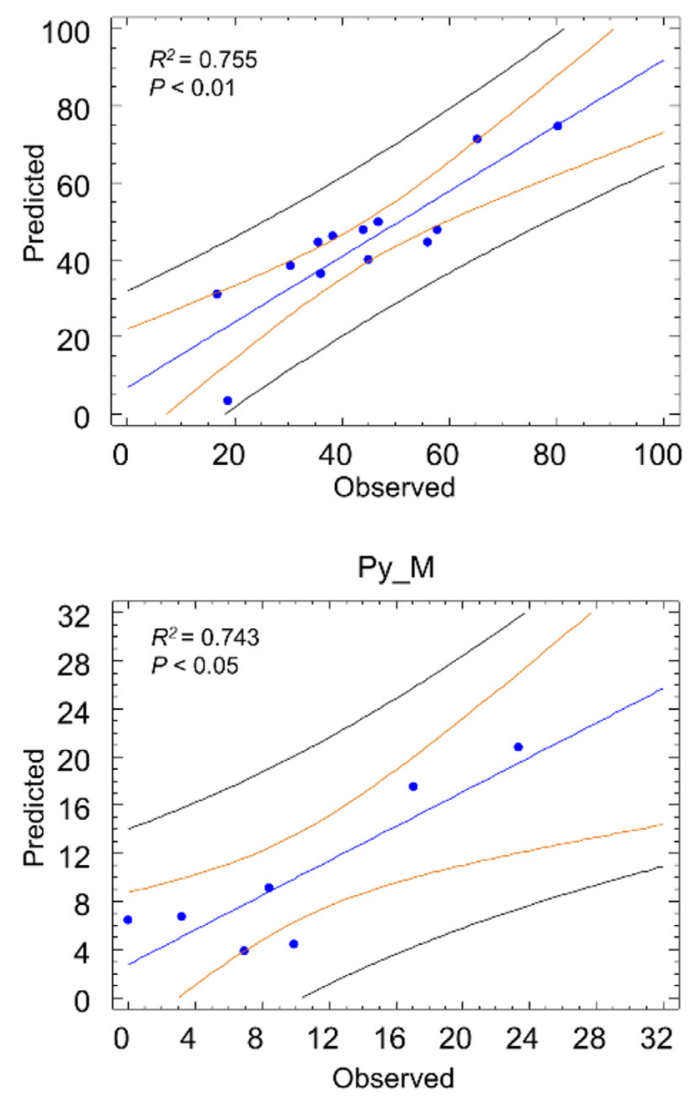

Fig. 3. Cross-validation plots between observed and predicted values obtained by partial least squares (PLS) regression using data from the infrared spectral range (1800-400 $\mathrm{cm}^{-1}$ ) to predict the alkyl C content independently calculated by ${ }^{13} \mathrm{C}$ NMR spectroscopy of soils (paddy soils, Histic Humaquept, Leptosols and Cambisols) and of laboratory-charred lignocellulosic biomass (Py_M).

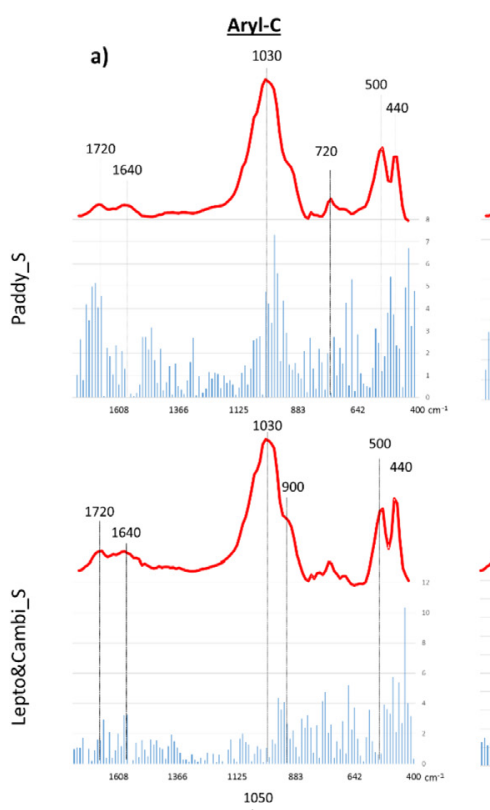

b) $\quad$ PyC
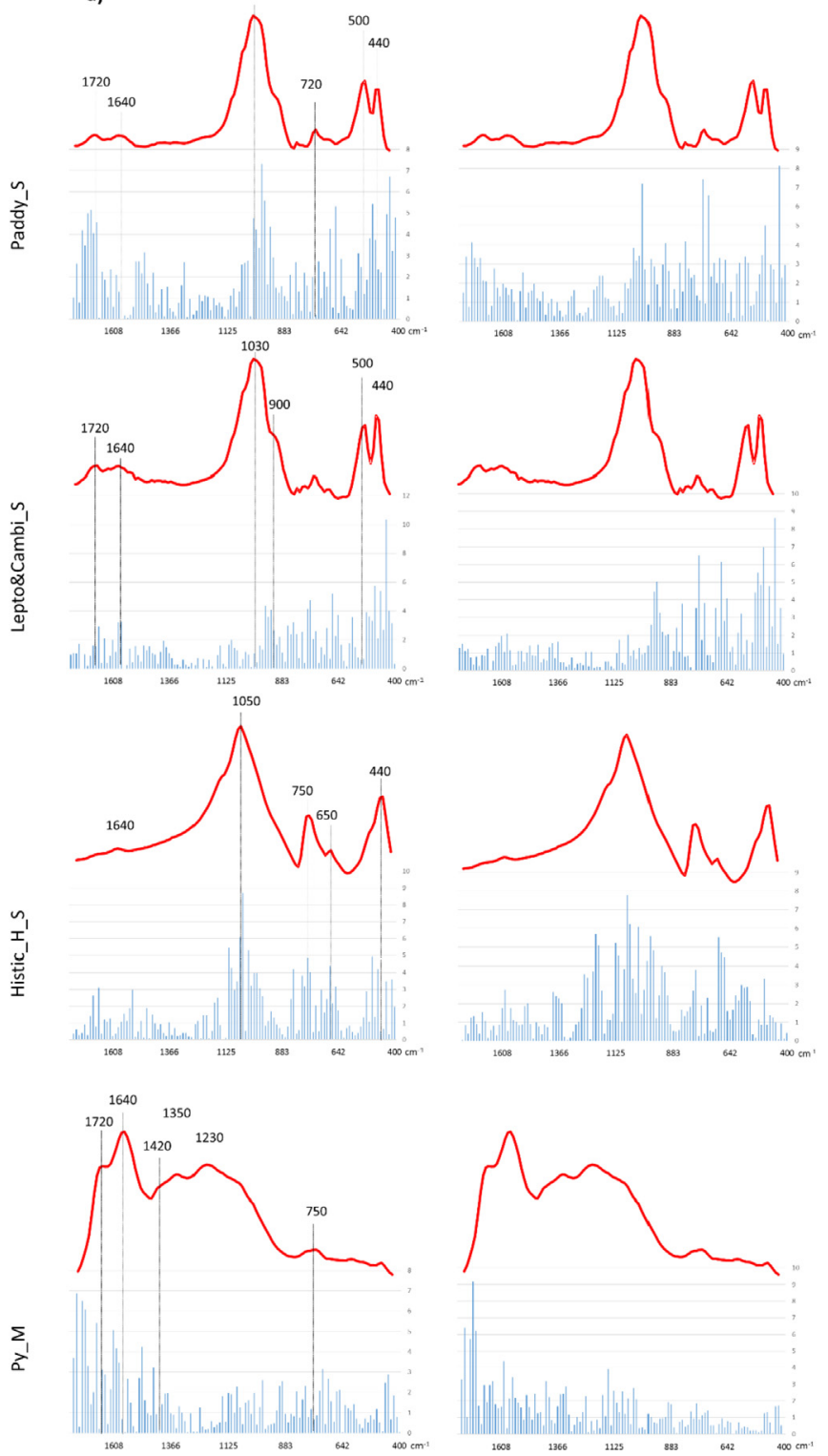

Fig. 4. Average IR spectra (red trace) and Variable Importance for Projection (VIP) of the different spectral points (bar plot) obtained in the partial least squares (PLS) models for a) aryl C content calculated by ${ }^{13} \mathrm{C}$ NMR spectroscopy and b) pyrogenic carbon content.

\section{Appendix A. Supplementary data}

Supplementary data to this article can be found online at https:// doi.org/10.1016/j.jenvman.2019.109567.

\section{References}

Akaike, H., 1974. A new look at the statistical model identification. IEEE Trans. Autom. Control 19, 716-723. https://doi.org/10.1007/978-1-4612-1694-0_16.

Cao, Z., Ding, J., Hu, Z., Knicker, H., Kögel-Knabner, I., Yang, L., Yin, R., Lin, X., Dong, Y., 2006. Ancient paddy soils from the neolithic age in China's Yangtze River Delta. 
Naturwissenschaften 93, 232-236. https://doi.org/10.1007/s00114-006-0083-4.

De la Rosa, J.M., Knicker, H., López-Capel, E., Manning, D.A.C., González-Pérez, J.A., González-Vila, F.J., 2008a. Direct detection of black carbon in soils by Py-GC/MS carbon-13 NMR spectroscopy and thermogravimetric techniques. Soil Sci. Soc. Am. J. 72, 258-266. https://doi.org/10.2136/sssaj2007.0031.

De la Rosa, J.M., González-Pérez, J.A., Hatcher, P.G., Knicker, H., González-Vila, F.J., 2008b. Determination of refractory organic matter in marine sediments by chemical oxidation, analytical pyrolysis and solid-state ${ }^{13} \mathrm{C}$ nuclear magnetic resonance spectroscopy. Eur. J. Soil Sci. 59, 430-438. https://doi.org/10.1111/j.1365-2389.2007. 00979.x.

De La Rosa, J.M., Sánchez García, L., de Andrés, J.R., González-Vila, F.J., González-Pérez, J.A., Knicker, H., 2011. Contribution of black carbon in recent sediments of the Gulf of Cadiz. Applicability of different quantification methodologies. Quat. Int. 243, 264-272. https://doi.org/10.1016/j.quaint.2011.01.034.

Fengel, D., Wegener, G., 1984. Wood, Chemistry, Ultrastructure, Reactions. De Gruyter, New York, pp. 613.

Fernández-Getino, A.P., Hernández, Z., Piedra Buena, A., Almendros, G., 2013. Exploratory analysis of the structural variability of forest soil humic acids based on multivariate processing of infrared spectral data. Eur. J. Soil Sci. 64, 66-79. https:// doi.org/10.1111/ejss.12016.

Gonçalves, C.N., Dalmolin, R.S.D., Dick, D.P., Knicker, H., Klamt, E., Kögel-Knabner, I., 2003. The effect of $10 \%$ HF treatment on the resolution of CPMAS ${ }^{13} \mathrm{C}$ NMR spectra and on the quality of organic matter in Ferralsols. Geoderma 116, 373-392. https:// doi.org/10.1016/S0016-7061(03)00119-8.

Hammes, K., Schmidt, M.W.I., Smernik, R.J., Currie, L.A., Ball, W.P., Nguyen, T.H., Louchouarn, P., Houel, S., Gustafsson, O., Elmquist, M., Cornelissen, G., Skjemstad, J.O., Masiello, C.A., Song, J., Peng, P., Mitra, S., Dunn, J.C., Hatcher, P.G., Hockaday, W.C., Smith, D.M., Hartkopf-Fröder, C., Böhmer, A., Lüer, B., Huebert, B.J., Amelung, W., Brodowski, S., Huang, L., Zhang, W., Gschwend, P.M., Flores-Cervantes, D.X., Largeau, C., Rouzaud, J.-N., Rumpel, C., Guggenberger, G., Kaiser, K., Rodionov, A., Gonzalez-Vila, F.J., Gonzalez-Perez, J.A., De la Rosa, J.M., Manning, D.A.C., López-Capél, E., Ding, L., 2007. Comparison of quantification methods to measure fire-derived (black/elemental) carbon in soils and sediments using reference materials from soil, water, sediment and the atmosphere. Glob. Biogeochem. Cycles 21, GB3016. https://doi.org/10.1029/2006GB002914.

Hernández, Z., Almendros, G., 2012. Biogeochemical factors related with organic matter degradation and C storage in agricultural volcanic ash soils. Soil Biol. Biochem. 44, 130-142. https://doi.org/10.1016/j.soilbio.2011.08.009.

Jiménez-González, M.A., Álvarez, A.M., Carral, P., Almendros, G., 2019. Chemometric assessment of soil organic matter storage and quality from humic acid infrared spectra. Sci. Total Environ. 341, 1160-1168. https://doi.org/10.1016/j.scitotenv. 2019.06.231.

Jones, M.W., Santín, C., van der Werf, G.R., Doerr, S.H., 2019. Global fire emissions buffered by the production of pyrogenic carbon (in press). https://doi.org/10.1038/ s41561-019-0403-x.

Knicker, H., 2007. How does char input affect the nature and stability of soil organic nitrogen and carbon? - a review. Biogeochemistry 85, 91-118. https://doi.org/10. 1007/s10533-007-9104-4.

Knicker, H., 2010. "Black nitrogen" - an important fraction in determining the recalcitrance of charcoal. Org. Geochem. 41, 947-950. https://doi.org/10.1016/j. orggeochem.2010.04.007.

Knicker, H., Müller, P., Hilscher, A., 2007. How useful is chemical oxidation with dichromate for the determination of "Black Carbon" in fire-affected soils? Geoderma 142, 178-196. https://doi.org/10.1016/j.geoderma.2007.08.010.

Knicker, H., González-Vila, F.J., González-Vázquez, R., 2013. Biodegradability of organic matter in fire-affected mineral soils of Southern Spain. Soil Biol. Biochem. 56, 31-39. https://doi.org/10.1016/j.soilbio.2012.02.021

Lasslop, G., Coppola, A.I., Voulgarakis, A., Yue, C., Veraverbeke, S., 2019. Influence of fire on the carbon cycle and climate. Curr. Clim. Change Rep. 5, 112-123. https:// doi.org/10.1007/s40641-019-00128-9.

Leifeld, J., 2006. Application of diffuse reflectance FT-IR spectroscopy and partial least squares regression to predict NMR properties of soil organic matter. Eur. J. Soil Sci. 57, 846-857. https://doi.org/10.1111/j.1365-2389.2005.00776.x.

Leng, L., Huang, H., Li, H., Li, J., Zhou, W., 2019. Biochar stability assessment methods: a review. Sci. Total Environ. 647, 210-222. https://doi.org/10.1016/j.scitotenv.2018. 07.402 .

López-Martín, M., González-Vila, F.J., Knicker, H., 2018. Distribution of black carbon and black nitrogen in physical soil fractions from soils seven years after an intense fores fire and their role as C sink. Sci. Total Environ. 637-638, 1187-1196. https://doi org/10.1016/j.scitotenv.2018.05.084.

Masiello, C.A., Druffel, E.R.M., 1998. Black carbon in deep-sea sediments. Science 280, 1911-1913. https://doi.org/10.1126/science.280.5371.1911.

Michaell, A.J., 1988. Second derivative F.T.-I.R. spectra of celluloses I and II and related mono- and oligosaccharides. Carbohydr. Res. 173, 185-195.

Miralles, I., Ortega, R., Sánchez-Marañon, M., Soriano, M., Almendros, G., 2007. Assessment of biogeochemical trends in soil organic matter sequestration in Mediterranean calcimorphic mountain soils (Almería, Southern Spain). Soil Biol. Biochem. 39, 2459-2470. https://doi.org/10.1016/j.soilbio.2007.04.017.

Parolo, M.E., Savini, M.C., Loewy, R.M., 2017. Characterization of soil organic matter by FT-IR spectroscopy and its relationship with chlorpyrifos sorption. J. Environ. Manag. 196, 316-322. https://doi.org/10.1016/j.jenvman.2017.03.018.

4 PER 1000 https://www.4p1000.org/(accessed 5 August 2019).

Poirier, N., Derenne, S., Rouzaud, J.N., Largeau, C., Mariotti, A., Balesdent, J., Maquet, J., 2000. Chemical structure and sources of the macromolecular, resistant, organic fraction isolated from a forest soil (Lacadée, south-west France). Org. Geochem. 31, 813-827. https://doi.org/10.1016/S0146-6380(00)00067-X.

Russell, F.E., Boyle, J.F., Chiverrell, R.C., 2019. NIRS quantification of lake sediment composition by multiple regression using end-member spectra. J. Paleolimnol. 62, 73-88. https://doi.org/10.1007/s10933-019-00076-2.

Santín, C., Doerr, S.H., Kane, E.S., Masiello, C.A., Ohlson, M., Rosa, J.M., Preston, C.M., Dittmar, T., 2016. Towards a global assessment of pyrogenic carbon from vegetation fires. Glob. Chang. Biol. 22, 76-91. https://doi.org/10.1111/gcb.12985.

Schmidt, M.W.I., Noack, A.G., 2000. Black carbon in soils and sediments: analysis, distribution, implications, and current challenges. Glob. Biogeochem. Cycles 14 777-794. https://doi.org/10.1029/1999GB001208.

Sisouane, M., Cascant, M.M., Tahiri, S., Garrigues, S., El Krati, M., Boutchich, G.E.K., Cervera, M.L., de la Guardia, M., 2017. Prediction of organic carbon and total nitrogen contents in organic wastes and their composts by infrared spectroscopy and partial least square regression. Talanta 167, 352-358. https://doi.org/10.1016/j. talanta.2017.02.034.

Terra, F.S., Viscarra Rossel, R.A., Demattê, J.A.M., 2019. Spectral fusion by outer product analysis (OPA) to improve predictions of soil organic C. Geoderma 335, 35-46. https://doi.org/10.1016/j.geoderma.2018.08.005.

Viscarra Rossel, R.A., 2008. ParLeS: software for chemometric analysis of spectroscopic data. Chemometr. Intell. Lab. Syst. 90, 72-83. https://doi.org/10.1016/j.chemolab. 2007.06.006.

World Reference Base for Soil Resources, 2014. International Soil Classification System for Naming Soils and Creating Legends for Soil Maps. World Soil Resources Reports No. 106. FAO, Rome.

Zimmermann, M., Leifeld, J., Fuhrer, J., 2007. Quantifying soil organic carbon fractions by infrared-spectroscopy. Soil Biol. Biochem. 39, 224-231. https://doi.org/10.1016/ j.soilbio.2006.07.010. 